\title{
El concepto de dignidad en las bienventuranzas para una aplicación en el contexto latinoamericano"
}

\author{
Hernán David Vásquez Amézquita** \\ Recibido: 30 de septiembre 2014 • Aprobado: 28 de noviembre 2014 \\ “Toda la teología de la liberación proviene del esfuerzo por dar sentido \\ al sufrimiento humano cuando aquellos que sufren son víctimas \\ de una opresión y explotación organizada, cuando son mutilados \\ y tratados como seres inferiores a lo que son: personas humanas, \\ creadas a imagen del Dios trino, redimidas por un solo Salvador \\ Jesucristo y santificadas por el Espíritu Santo" \\ -Gustavo Gutiérrez-
}

\section{Resumen}

Referirse al concepto de dignidad en el contexto latinoamericano resulta una tarea específica, porque las características sociales, políticas, económicas y culturales están marcadas por situaciones de injusticia y desigualdad social. La teología a lo largo de su reflexión y elaboración desde la perspectiva latinoamericana ofrece un aporte significativo con relación a este tema; por tanto, comprenden este artículo tres elementos de gran importancia, a saber: el concepto de dignidad, las bienaventuranzas, y la reflexión teológica desde Latinoamérica.

* Este trabajo es resultado de las investigacionnes realizada por el autor.

** Licenciado en Filosofía, Ética y Valores. Teólogo de la Universidad Santo Tomás y de la Universidad Pontificia Bolivariana. Fraile dominico del convento Enrique Lacordaire de Medellín, Colombia. Correo electrónico: hedava28@hotmail.com 
Lo que se pretende es evidenciar, cómo se interpreta y qué significa el concepto de dignidad en las bienaventuranzas proclamadas por Jesús en su sermón de la montaña, desde la perspectiva de Mateo, para una propuesta de comprensión desde el horizonte latinoamericano. Es una interpretación actual del sermón de la montaña bajo las premisas del pensamiento de la teología latinoamericana, que intenta responder a la cuestión de cómo ser cristiano en un continente lleno de maltrato y desfiguración del hombre que vive en condiciones de exclusión, ya que no hay circunstancia de vida humana, que lo alejen de la aceptación del amor gratuito de Dios, más que la propia experiencia de sufrimiento injusto.

Palabras clave: dignidad, bienaventuranzas, Dios, hombre, liberación.

\title{
The concept of dignity in the beatitudes for an application in the Latin American context
}

\begin{abstract}
Referring to the concept of dignity in the Latin American context is a specific task, because the social, political, economic and cultural characteristics are marked by situations of social injustice and inequality. Theology throughout its reflection and elaboration from the Latin American perspective offers a significant contribution with regards to this subject; therefore, this article comprises three elements of great importance, which are: the concept of dignity, the beatitudes, and the theological reflection from Latin America.

What is intended is to show, how is interpreted and what means the concept of dignity in the beatitudes proclaimed by Jesus in his Sermon on the Mount, from the perspective of Mathew, for an understanding proposal from the Latin American horizon. It is a current interpretation of the sermon on the mount under the premises of Latin American theology thinking, which tries to answer the question on how to be Christian in a continent full of abuse and disfigurement of man that lives in conditions of exclusion, since there are no circumstances of human life, that move him away from the acceptance of the free love of God, than the own experiencing of unfair suffering.
\end{abstract}

Keywords: Dignity, beatitudes, God, men, liberation. 


\section{Le concept de dignite dans la beatitude pour une application dans le contexte latinomamericain}

\section{Résumé}

Faire référence au concept de dignité dans le concept latino-américain s'avère une tâche spécifique, dès lors que les caractéristiques sociales, politiques, économiques et culturelles sont caractérisées par des situations d'injustice et d'inégalités sociales. La théologie tout au long de sa réflexion et élaboration depuis la perspective latino-américaine fourni un apport significatif en relation avec ce sujet; cet article comprend par conséquence trois éléments de grande importance, à savoir: le concept de dignité, la béatitude et la réflexion théologique depuis l'Amérique Latine.

On prétend mettre en évidence, l'interprétation et le sens du concept de dignité dans la béatitude proclamée par Jésus dans son sermon de la montagne, depuis la perspective de Mattieu, pour une proposition de compréhension depuis l'horizon latino-américain. C'est une interprétation actuelle du sermon de la montagne sous les postulats de la pensée de la théologie latino-américaine, qui essaye de répondre à la question de comment être chrétien dans un continent rempli de mauvais traitements et défigurement de l'homme, qui vit en conditions d'exclusion, puisqu'il n'y a pas de circonstances de vie humaine, qui l'éloignent de l'acceptation de l'amour gratuit de Dieu, d'autre que la propre expérience de la souffrance injuste.

Mots-clés: Dignité, béatitude, Dieu, homme, libération

\section{Introducción}

En medio de una sociedad latinoamericana que se encuentra en situación de injusticia y desigualdad social, surge la pregunta, ¿cuál es el concepto de dignidad a partir de las palabras de Jesús en el sermón de la montaña para el contexto latinoamericano?, a lo que corresponde tener una mirada desde la perspectiva teológica latinoamericana, que se ha encargado de considerar a Dios y al hombre desde este específico horizonte de comprensión.

Es preciso reconocer que una dificultad que se presenta actualmente en lo concerniente al estudio de la teología latinoamericana, y por ende de la liberación ${ }^{1}$, es que para muchos, ésta 'ha pasado de moda'; consideración que tengo

1 Conviene aclarar que la teología de la liberación se enmarca dentro de la teología latinoamericana. 
como absurda, pues, las diversas perspectivas teológicas que a lo largo de la historia han surgido no pueden reducirse a una cuestión de moda. No obstante, para trabajar desde la apreciación de que la teología de la liberación ha pasado de moda, principalmente en ambientes ultraconservadores, dicha condición liberadora en teología brinda elementos esenciales de gran utilidad, para una comprensión evangélica de la realidad latinoamericana.

El concepto de dignidad casi siempre se revisa desde parámetros antropológico-filosóficos, dejando a un lado la palabra de Dios, o mejor, la reflexión teológica, que afirma la salvación y exaltación del hombre; agrego que tal vez este descuido $u$ olvido se debe a la frenética resolución de la modernidad de dejar a un lado, todo lo que tenga que ver con religión, Dios, cielo, trascendencia, etc., porque desde este punto de vista de secularización, se llega a la opresión del hombre.

Sin embargo, si hay que hacer una claridad, es definitivamente afirmar que la palabra de Dios, en ningún momento, pretende oprimir al hombre; más bien lo contrario, busca exaltarlo y mostrarle que su vida tiene un sentido propio, a los ojos de los demás y a los ojos del mismo Dios. Por ello, es conveniente hacer un estudio de la dignidad a partir de las bienaventuranzas, porque podrían brindar aspectos vitales para una comprensión viva, actual y eficaz de la dignidad del hombre.

Tres elementos de gran importancia comprenden este escrito: el concepto de dignidad, las bienaventuranzas, y la teología de la liberación. Lo que se quiere con relación a los dos primeros elementos, es evidenciar cómo se interpreta y se significa el concepto de dignidad en las bienaventuranzas proclamadas por Jesús en su sermón de la montaña, desde la perspectiva de Mateo. En lo concerniente al tercer elemento antes mencionado, hay que decir que este trabajo va a desarrollarse bajo la línea de la teología de la liberación, en cuanto que sirve para consolidar una verdadera llamada a la libertad del hombre latinoamericano.

En pocas palabras, es una interpretación actual del sermón de la montaña, bajo las premisas del pensamiento de la teología de la liberación, que intenta responder a la cuestión: ¿cómo ser cristiano en un continente lleno de maltrato y desfiguración del hombre que vive en condiciones de exclusión?, pues, "no hay circunstancia humana, en verdad, que nos ponga a mayor distancia de la aceptación del amor gratuito de Dios que nuestra propia experiencia del sufrimiento, en particular si es injusto" (Gutiérrez, 1986, p. 59).

De esta manera, la propuesta con esta investigación, es mostrar al hombre latinoamericano su condición de dignidad. Que a pesar de las situaciones particulares, sociales y económicas que esté viviendo, la palabra de Dios se convierte 
en signo de fe, esperanza y amor que empuja a una comprensión mayor del sentido de la vida.

Ahora bien, si la propuesta de la teología de la liberación se caracteriza por hacer del hombre un ser libre que sea capaz de creer en Dios a partir de la realidad inmediata que le rodea, también es necesario tener en cuenta que el concepto de dignidad, aquí adquiere importancia fundamental. Y respecto de esto, la misma palabra de Dios, en este caso el sermón de la montaña, brinda los parámetros necesarios para que el hombre pueda realizarse como tal.

Por consiguiente, se resaltan los siguientes apartados en los que se va a profundizar para que sean propiciadores de lo que se quiere con este escrito: comprensión de la noción dignidad (1), dignidad como liberación (2), comprensión de Dios para América Latina (3), dignidad en las bienaventuranzas (4), bienaventuranzas para América Latina (5), y Conclusión (6).

\section{Comprensión de la noción Dignidad}

Llegar a una fundamentación del concepto de dignidad resulta una tarea muy difícil, porque hay distintas fundamentaciones epistemológicas que el hombre en el transcurrir de la historia ha propuesto. Por ejemplo, una fundamentación metafísica, para algunos carece de sentido, porque se queda en lo abstracto y no tiene asidero en la realidad; para otros, una fundamentación empírica se queda con lo meramente comprobable o verificable. Sin embargo, el hecho de que haya diversas formas de fundamentación no debe verse como una cuestión de inseguridad a la hora de definir o sustentar, qué es la dignidad, sino como una posibilidad de riqueza que permite una mayor consolidación. Además es preciso anotar, que aunque no hay una fundamentación consensual, no implica la imposibilidad de hablar de fundamentación o fundamentaciones.

Es así que, Fuster Camp parte de una premisa que comprende las características del hombre, al afirmar que "la dignidad es una noción filosófica fundamental de la persona" (Fuster, 2010; p. 191). Y en este sentido, se puede verificar lo afirmado, porque de distintas formas y modos las diversas tradiciones, tanto filosóficas como teológicas, han dedicado un espacio importante para dar cuenta de la persona y su dignidad.

Hay dos clases de dignidad, según lo plantea este autor: la dignidad ontológica y la dignidad moral. La primera, entiende la dignidad como propiedad innegociable del ser personal y no como una mera decisión social de consenso. La segunda, en cambio, la conquista cada persona por medio de su libertad, es decir, 
que ha sido capaz de valerse por sí misma con convicción propia en la búsqueda de la verdad y el bien. Estas dos clases de dignidad no son contrarias, sino que pueden tenerse como complemento la una de la otra.

Cuando se habla de dignidad debe tenerse en cuenta que la persona tiene un valor absoluto y es fin en sí misma; aspectos que tanto la moral como la ontología comparten y afirman al momento de definir la comprensión de cada una. A propósito de aquello que une y aquello que no tanto, hay ciertos rasgos característicos de cada perspectiva de fundamento, así:

- Desde la época clásica, dos elementos constituyen el fundamento de la dignidad: la intimidad cognoscitiva y la amorosa del ser humano. Aquí hay una correspondencia con la naturaleza espiritual de la persona. “El hombre tiene las capacidades inauditas de conocer la realidad en sí y de querer por sí lo real, queriéndolo por sí mismo." (Fuster, 2010; p. 191). Es decir, que voluntad de amar y conocimiento en el hombre son elementos en los que se funda la dignidad. Es una categoría pasiva que lleva a comprender que el hombre es digno, en la medida en que es conocido y amado.

- Con Kant hay una intuición de la verdad de la dignidad, pues la persona no debe ser nunca considerada como un medio, sino como un fin. Sin embargo, "el pensamiento ético kantiano está imposibilitado para el fundamento metafísico de la dignidad" (Fuster, 2010; p. 194). Es más bien un imperativo ético de natural exigencia de la razón práctica, que siendo un gran principio se queda en el vacío, ya que carece de un aporte hermenéutico adecuado de la dignidad.

- $\quad$ Para Karol Wojtyla hay una norma personalista, que es fórmula sublime: "La persona es un bien respecto del cual sólo el amor constituye la actitud apropiada y valedera" (Fuster, 2010; p. 194). Esto se funda en la idea o consideración ética de la persona como bien en sí mismo y además que busca el bien de la persona como fundamento verdadero de toda ética.

- "La tradición judeo-cristiana fue la matriz histórica en la que se forjó la noción de dignidad." (Fuster, 2010; p. 194). Es decir la fundamentación está en el hecho del hombre ser creado a imagen y semejanza de Dios; es ontológica esta fundamentación. "La creación originaria del ser personal constituye la fuente última de la dignidad de la persona humana." (Fuster, 2010; p. 194). 


\section{Dignidad como liberación}

La dignidad desde la perspectiva en la realidad latinoamericana y en lo que se ha planteado, a partir del análisis de una teología propia, se entiende muchas veces desde el sentido de liberación; por esto:

La corriente de la liberación expresada en las profundas y legítimas aspiraciones de nuestros pueblos es interpretada en un sentido de fe pascual: "así como otrora, el primer pueblo, experimentaba la presencia salvífica de Dios cuando lo liberaba de la opresión de Egipto, cuando lo hacía pasar el mar y lo conducía hacia la tierra de la promesa, así también nosotros, nuevo pueblo de Dios, no podemos dejar de sentir su paso que salva, cuando se da el verdadero desarrollo, que es el paso para cada uno y para todos, de condiciones de vida menos humanas, a condiciones de vida más humanas..." (López Trujillo, 1974; p. 173).

Cabe decir que, cuando hablamos de liberación, es necesario tener en cuenta lo que concierne al sentido de fe pascual, porque permite abrir un horizonte de comprensión desde la experiencia que vivió el pueblo de Israel en su historia de salvación, y así es posible hacer una relación de la experiencia que vive el pueblo latinoamericano. Por otro lado, parece curioso tomar una frase de López Trujillo, quien ha sido reacio a ciertas ideas de los fundamentos de la teología de la liberación; sin embargo, es preciso afirmar que aunque haya distintas fundamentaciones epistemológicas, la idea que se presenta aquí no es de carácter contradictorio a las pretensiones de la corriente teológica de la liberación.

Con relación a los pobres que son quienes se encuentran en situación de desigualdad y sufrimiento, se plantea en lo concerniente a la dignidad, que ésta debe ser rescatada tal como:

Esa Buena Nueva que anunció Jesús en el Sermón de las Bienaventuranzas, que dan pleno sentido y valor a las limitaciones humanas: materiales, físicas, síquicas y sobrenaturales. Todas ellas, aceptadas como permitidas por el Padre para nuestra purificación, superación de nuestra egolatría endémica y entrega amorosa y filial a los designios de Dios, nos llevan a la verdadera felicidad, la cual no está en tener más, sino en ser más por la participación real, ya aquí en la tierra, de la vida misma divina. Alegraos y regocijaos -exclama Jesús ante la perspectiva que el Padre ofrece a los humanos- porque vuestra recompensa será grande en los cielos, Mt 5,12 (Lepeley, 1987; p. 102). 
El pobre no debe centrarse en la miseria de su situación, sino en medio de ella, encontrar el camino para ser feliz, para regocijarse de que su vida no es un castigo; debe fijar su mirada en que si bien hay sufrimiento y miseria, ésta no debe definir lo sufrido y miserable que es, pero sí lo feliz que puede ser en esta situación. Es una perspectiva evangélica que se caracteriza por ser esperanzadora.

Así mismo, desde una perspectiva contextual hay que decir que:

En el ambiente del Tercer Mundo y especialmente Latinoamericano, la relación Dios/hombre se plantea en una problemática nueva: en la situación de un continente en sub-desarrollo, causado por el desarrollo, lo cual implica una dependencia económica, política, cultural y religiosa. La liberación surge como la necesidad y la urgencia para desencadenar el proceso de recuperación y conquista de la libertad: liberación de un sistema global de injusticia, opresivo y discriminador: liberación para la auto-realización del pueblo, de modo que él mismo pueda determinar su destino y su historia. En esta perspectiva, la cuestión es: la salvación de Dios por Cristo, ¿es liberación humana? Los términos de la relación Dios/hombre son no solo de cuño comunitario y eclesial, sino socio-político. Que, en definitiva desembocan en esta dualidad: salvación de Dios por Cristo y liberación socio-política, praxis de fe y praxis política (Gutiérrez, 1989; p. 193).

El hombre latinoamericano debe mirar su contexto vital desde las categorías sociales, políticas y económicas que irrumpen en su vida; y no por modelos primermundistas, que no atienden a lo real de su experiencia de vida cotidiana, que muestra desde una perspectiva desesperanzadora, que le falta mucho para llegar a ellos. La mejor opción es reconocer que no es igual a otros contextos y desde allí hacer un proceso en el cual aprenda a vivir desde lo que se tiene, aspirando a mejorar siempre la calidad de vida.

\section{Comprensión de Dios para América Latina}

Para abordar un horizonte de comprensión de Dios desde la perspectiva latinoamericana es conveniente recurrir a la obra de Gustavo Gutiérrez titulada: Hablar de Dios desde el sufrimiento del inocente, una reflexión sobre el libro de Job, puesto que ésta pretende recoger los elementos específicos del hombre sufriente que busca a Dios.

A la pregunta, cómo hablar de Dios en una realidad de pobreza, injusticia y sufrimiento, que se torna complicada, puesto que "no hay circunstancia humana, 
en verdad, que nos ponga a mayor distancia de la aceptación del amor gratuito de Dios que nuestra propia experiencia del sufrimiento, en particular si es injusto" (Gutiérrez, 1986; p. 59), hay que decir que "toda la teología de la liberación proviene del esfuerzo por dar sentido al sufrimiento humano cuando aquellos que sufren son víctimas de una opresión y explotación organizada, cuando son mutilados y tratados como seres inferiores a lo que son: personas humanas, creadas a imagen del Dios trino, redimidas por un solo Salvador Jesucristo y santificadas por el Espíritu Santo" (Gutiérrez, 1986; p. 19).

Son las mismas reflexiones que surgen de los pobres las que hacen que exista la teología de la liberación, porque justamente, ésta nace para generar un proceso de transformación. Gustavo Gutiérrez muestra que dentro del contexto latinoamericano es necesario analizar el libro de Job, pues, el protagonista de este texto tiene mucho que enseñarnos en lo concerniente a nuestra relación con Dios, aplicado a un contexto latinoamericano. Esto desde la mirada bíblica que nos interpela, penetra y escruta los pensamientos del corazón; es así que se profundiza en Job el hablar de Dios al hombre sufriente.

Así pues, más que hacer una exposición explícita de lo que Job puede decir a la sociedad latinoamericana, lo que se hace es tomarlo como "fuente que señala una problemática, plantea interrogantes, anima un proceso, pero que espera también una iluminación e interpelación desde la palabra de Dios" (Gutiérrez, 1986; p. 29). Por esta razón, es preciso tener en cuenta tres aspectos que el libro de Job ofrece:

\section{a. La Apuesta}

Dentro de este apartado lo que se propone es evidenciar que el hombre en su sufrimiento es capaz de afirmar su fe en Dios de manera desinteresada. Por esta razón, se centra en la cuestión de maldecir o bendecir a Dios desde una situación de sufrimiento. Esto lo está viviendo Job, quien siendo religioso y apartado del mal es capaz de bendecir a Dios, no solo, porque su vida va en un camino próspero, sino porque es su Señor. De allí que, el Señor acepta el reto de Satán porque confía en Job.

Por otro lado, hay que tener en cuenta que para Satán el hombre religioso no es más que un interesado que busca alabar a Dios para obtener retribución. El señor quiere mostrar que esto no es así. El propósito de esta apuesta se enmarca en la centralidad de porqué ser religioso, ya que si se es por retribución se cae en una interpretación demoníaca de la religión. El desinterés es lo central en este apartado, por lo cual Job es paradigma perfecto. 
El comienzo del sufrimiento de Job por la pérdida de sus hijos y bienes genera una decepción en Satán, ya que no maldice a Dios. Luego, con el ataque al propio cuerpo de Job y con la muerte de su esposa, éste sigue manteniéndose en la honradez. Hay que resaltar que Job pasó a ser de los excluidos y, sin embargo, no dejó de afirmar su fe. Esta experiencia que está viviendo Job, sirve para que en nuestra condición social latinoamericana aprendamos la virtud de la honradez.

Hay que denotar aquí la esperanza que mantiene a Job en medio de los grandes sufrimientos padecidos. Aunque maldice muchas cosas como el día en que nació jamás lo hace con Dios. Se resalta por la actitud de Job, la experiencia en donde desde el sufrimiento que podemos reconstruir el deseo de justicia. Invita esto a que por más sufrimiento, injusticia y dolor que haya en nuestra vida, lo importante es que la esperanza se aferre cada vez más.

Para mostrar la forma en que Job habla del Señor, el texto hace uso de la vía negativa que usan los amigos, quienes con sus discursos teológicos de defensa del Señor, lo que hacen es hablar en vano, porque no atienden a lo que el mismo Job está viviendo, es él quien en última instancia sabe hacer uso de un lenguaje propio, en medio del sufrimiento, para poder afirmar a Dios en dicha circunstancia.

"Hablar de Dios desde el sufrimiento del inocente no es un asunto que se limite al caso de Job, es un desafío para todo creyente" (Gutiérrez, 1986; p. 53). Si bien es cierto "el dolor humano es el terreno duro y exigente en el que se hace la apuesta sobre el hablar acerca de Dios" (Gutiérrez, 1986; p. 62), no podemos afirmar que hay una imposibilidad de hablar de Dios en esta realidad. Hay que partir de que a Dios no se le debe encasillar en categorías humanas, es decir, no podemos hablar de castigo, como lo hacen algunos cuando están en la tribulación.

$\mathrm{Si}$ "la apuesta de Job arranca desde el basurero de la ciudad para encontrar un lenguaje apropiado acerca de Dios" (Gutiérrez, 1986; p. 64), para Latinoamérica, esta apuesta comienza desde los pobres de la tierra, teniendo claro que de manera constante somos llamados a lo inesperado. Esto sobre el lenguaje para referirnos a Dios, se invita claramente a una reivindicación con el que sufre, no de la manera de los amigos de Job, sino con gestos concretos de solidaridad hacia el atribulado.

\section{b. El lenguaje profético}

Aquí se pretende discurrir acerca de la importancia o no de la retribución temporal, puesto que se cuestiona ésta. Parece que dentro de la doctrina de la retribución temporal, aquel que es pobre ha sido pecador y por eso le va de esa 
manera, pensamiento típico veterotestamentario. $Y$ hoy día aún encontramos que "ciertas tendencias dentro del mundo cristiano han dado nueva vida a lo largo de la historia a esta concepción ética que ve en la riqueza un premio de Dios al hombre honesto y trabajador, y en la pobreza un castigo al pecador y al ocioso" (Gutiérrez, 1986; p. 74), olvidándose del carácter profético previo a Jesús y propio del Maestro.

Esto indica una de las razones del porqué el hombre es indiferente a la situación del pobre, que cree está recibiendo su merecido por sus actos; así pasa en una parte de nuestra sociedad latinoamericana, sobre todo la que no sufre y tiene la vida medio resuelta.

Hay que tener en cuenta que precisamente la vivencia del sufrimiento desde la inocencia hace que esta doctrina de la retribución sea inútil, así pasa muchas veces con las teologías que, aunque certeras, no atienden a la realidad inmediata de quien la recibe. La situación que Job vive ya no se ve como una situación individual, sino que se abre su comprensión a todos los pobres que se encuentran en situación de sufrimiento e injusticia. Por eso se convierte esto en una denuncia a aquellos que ostentan el poder y que no saben ayudar al necesitado, y no en un reclamo a Dios porque no soluciona esta situación.

Job resignifica la relación de Dios con el pobre, y afirma la necesidad del servicio a los pobres. Es decir, que si se quiere hablar de justicia es necesario hacerla real y no abstracta por medio de la ayuda a los pobres. Desde esta perspectiva es posible que el hombre hable de igualdad ante Dios. "El compromiso con el pobre proporciona un terreno firme para un lenguaje de carácter profético sobre Dios" (Gutiérrez, 1986; p. 121). En este sentido un salir de sí mismo es aspecto fundamental para hablar de Dios desde la injusticia y el dolor, desde la denuncia profética y la acción comprometida.

\section{c. El lenguaje de la contemplación}

El lenguaje de la contemplación como el profético son esenciales para hablar de Dios desde el sufrimiento. Pero para esto hay que aclarar la idea de resignación, porque no se trata de un conformismo, sino de una profunda confianza en el actuar de Dios, sobre todo desde la vida de quien sufre. El lenguaje contemplativo muchas veces ha propiciado erradamente esta idea. Si alguien muere, la expresión "Dios me lo dio, Dios me lo quitó" indica una confianza en Dios, mas no una resignación. 
El reclamo que Job le hace a Dios, indica firmeza en quien cree al hablarle con la verdad. En este sentido paradójico "Job reconoce que Dios juzga el comportamiento humano, pero percibe que su misericordia es más grande que su justicia o, para ser más exacto, que la justicia de Dios se entiende solamente al interior de su amor primero y gratuito" (Gutiérrez, 1986; p. 148). Es un crecimiento de la fe, que se da gracias al proceso de sufrimiento. Explica que aquellos que necesitan más son los que más se abandonan a la providencia de Dios.

El primer paso de la fe popular implica la profundización de una confianza total en Dios. Es el paso para que Dios hable en la vida de aquel que sufre. Se da el encuentro de dos libertades, la de la queja de Job y la del hablar de Dios. Esto de las libertades se entiende en que "la libertad de Job se expresa en su queja y rebelión, la libertad de Dios se revela en la gratuidad de su amor que no se deja encerrar en un sistema de premios y castigos predecibles" (Gutiérrez, 1986; p. 177).

La finalidad de la rebeldía de Job, por su experiencia de sufrimiento e injusticia, culmina en el hecho de que ha podido contemplar a Dios. Por eso "Dios le ha revelado su designio y el sentido de una justicia que no está presa en la camisa de fuerza de la doctrina de la retribución" (Gutiérrez, 1986; p. 188).

La experiencia de sufrimiento en Job tiene un proceso. Después de los alegatos con Dios, ya no "lo conoce de oídas" y lo pudo contemplar. De ahí que "lo que debía hacer era saltar el cerco que le había puesto esa anquilosada y peligrosamente idolátrica teología, correr libre por el campo del amor de Dios y respirar a todo pulmón como aquellos animales no domesticables por el ser humano que Dios describe en su alegato" (Gutiérrez, 1986; p. 194).

Desde siempre se ha buscado dar explicación al sentido del sufrimiento y al sentido cristiano del mismo. Pero no se puede encontrar una explicación definitiva al problema del sufrimiento, porque esta experiencia presenta una complejidad. Sin embargo, desde la teología latinoamericana se afirma la necesidad de un lenguaje para hablar con y de Dios, desde la situación de injusticia y sufrimiento.

“El lenguaje profético permite aproximarse a un Dios que ama con predilección al pobre, precisamente porque su amor no se deja encerrar en las categorías de la justicia humana" (p. 205). Mientras que "el lenguaje de la contemplación reconoce que todo viene del amor gratuito del Padre y abre nuevos horizontes de esperanza" (Gutiérrez, 1986; p. 211).

Por consiguiente, "nos toca hacer nuestro propio itinerario en las condiciones presentes del dolor y la esperanza del pueblo pobre de América Latina, analizar su relación con la necesaria eficacia histórica y sobretodo confrontarla nuevamente con la Palabra de Dios"' (Gutiérrez, 1986; p. 223). 
En este sentido, lo fundamental es ver la colectividad del problema que atañe a la sociedad latinoamericana. Hacer algo y no quedarse de brazos cruzados. Para esto es un imperativo teológico y experiencial unificar el lenguaje contemplativo y el profético.

\section{La Dignidad en las Bienaventuranzas}

El sermón de la montaña de Jesús, dice²:

${ }^{1}$ Viendo la muchedumbre, subió al monte, se sentó, y sus discípulos se le acercaron. ${ }^{2} Y$ tomando la palabra, les enseñaba diciendo:

${ }^{3}$ «Bienaventurados los pobres de espíritu, porque de ellos es el Reino de los Cielos.

${ }^{4}$ Bienaventurados los mansos, porque ellos poseerán en herencia la tierra.

${ }^{5}$ Bienaventurados los que lloran, porque ellos serán consolados.

${ }^{6}$ Bienaventurados los que tienen hambre y sed de la justicia, porque ellos serán saciados.

${ }^{7}$ Bienaventurados los misericordiosos, porque ellos alcanzarán misericordia.

${ }^{8}$ Bienaventurados los limpios de corazón, porque ellos verán a Dios.

${ }^{9}$ Bienaventurados los que trabajan por la paz, porque ellos serán llamados hijos de Dios.

${ }^{10}$ Bienaventurados los perseguidos por causa de la justicia, porque de ellos es el Reino de los Cielos.

${ }^{11}$ Bienaventurados seréis cuando os injurien, y os persigan y digan con mentira toda clase de mal contra vosotros por mi causa. ${ }^{12}$ Alegraos y regocijaos, porque vuestra recompensa será grande en los cielos; pues de la misma manera persiguieron a los profetas anteriores a vosotros.»

2 Evangelio de Mateo 5, 1-12, en la Biblia de Jerusalén. 
Lo que Jesús quiere con estas palabras es hacernos un llamado a la dicha. Parece que esta llamada ha llegado a convertirse en "una religión triste, en una religión de obligaciones" (Dupont, 1997; p. 4), porque más que una comprensión de llamado a la dicha se ha convertido en palabras de consuelo conformista, pues, "por un trágico contrasentido, han servido muchas veces en el curso de las edades, para mantener y amparar un orden social injusto, como si Jesús declarase: ¡Qué gran suerte tenéis de ser pobres! ¡Seguid siéndolo toda vuestra vida, y ya veréis más tarde en el cielo, cómo os recompensa Dios!" (Dupont, 1997; p. 5). Suena absurdo sólo pensar que Jesús tiene esta intención cuando da este sermón, que está cargado de profunda dicha esperanzadora, y no de un consuelo conformista.

La bienaventuranza es una fórmula de felicitación, en la Escritura aparece cuando se le dice a María: "Dichosa tú que has creído" (Lc 11, 27-28). Y esto, efectivamente, es lo que quiere decir Jesús: que las personas con las circunstancias que allí se plantean fueron dichosas, lo son o lo serán, porque en gran o poca medida cada uno pasa por una estancia de las bienaventuranzas, ya sea llorar, tener hambre, ser perseguido o misericordioso, etc. Hay que tener claro que está dicha de la cual se habla no significa que haya exclusión de contrariedades y sufrimientos. Es la invitación que hace Jesucristo para que el hombre se supere a sí mismo, es la oferta que muestra la magnificencia de la misericordia de Dios para con el hombre, es el gozo que disfruta el hombre que se sabe amado por Dios. Es el reconocimiento propicio que hace Dios del hombre al mostrarle cuán importante es para Él.

La referencia a la dignidad se encuentra expresada de manera explícita en el mismo Jesús, quien con su obra y palabras muestra lo que significa ser digno; Él es para el cristiano el modelo plausible de dignidad. Esa comprensión de ser digno la quiere manifestar en el sermón de la montaña. Y para poder vislumbrar esto hay que referirse a dos aspectos fundamentales que están contenidos en las bienaventuranzas: "Amaos unos a otros como yo os he amado" (Jn 13,34) y "Permaneced en mi amor" (Jn 15,9).

Significa que la dignidad es de Dios en cuanto que Él nos la da por habernos creado a imagen y semejanza suya, por habernos dado el ser (dignidad ontológica) y para eso Jesús es el ejemplo vivo de que el hombre es digno; y esta experiencia de saberse amado por Dios, hace que el hombre comunique ese amor que ha recibido por medio de acciones que lo vuelven más humano y también por la perseverancia en ese amor que ha recibido (dignidad moral). Son las bienaventuranzas expresión de la fidelidad a Dios, que permean el corazón del hombre y lo transforman haciéndolo más humano y más cercano a Dios, con el propósito de contemplar a Dios por medio del otro.

\section{Universidad Santo Tomás, Facultad de Teología}


Vivir las bienaventuranzas de corazón implica vivir en la felicidad que se muestra como un 'ya' y un 'todavía no' en plenitud. Es decir, el hombre reconoce que su vida está en busca del encuentro futuro con Dios, pero viviéndola desde las situaciones vitales circundantes.

La cuestión de la dignidad se refleja, porque esta perícopa rescata al hombre que sufre, al pobre, al hambriento, en cuanto que hay una promesa de salvación para ellos. Se trata de una respuesta que da el Señor a aquellos que con una ferviente súplica tienen un deseo natural de felicidad; y es por eso que ese deseo se satisface en Dios, quien pone en el corazón del hombre esa necesidad de acercarse a Él. Son los que se abandonan a la causa de Jesús, de su reino, los que aún en el sufrimiento, podrán ser bienaventurados, dignificados.

Por eso, "la dignidad esencial del hombre consiste en que dentro de una comunidad diferenciada, dentro de una historia espacio-temporal, este hombre, conociéndose espiritualmente y orientándose libremente hacia la inmediata comunidad personal con el Dios infinito, puede y debe abrirse al amor, que es comunicación de Dios en Jesucristo" (Rahner, 1961; p. 248)

Quien asume de corazón esas palabras de Jesús en el sermón de la montaña comprende que su vida se transforma. Comprende que en Dios hay cabida para todos los hombres, especialmente aquellos que están sedientos de Él, aquellos que sufren, aquellos que lloran, aquellos que aceptan esta invitación a ser bienaventurados, que eligen a Jesucristo, para que su gracia actúe. Son las bienaventuranzas una transformación de la conciencia que invita a actuar en favor de Dios y los hombres.

En este sentido, también se puede afirmar que más allá de la situación "temporal" de sufrimiento que se viva, son los preferidos y privilegiados por Dios; en ello está puesta su mirada, su corazón, y por tanto, son opción preferencial por los seguidores de Cristo, por el hecho de ser sus hijos e imagen y semejanza del creador. Quien es bienaventurado es fuente de inspiración para aquel que camina sin rumbo fijo; es evidencia de que la presencia y gracia de Dios actúa.

Debido a esto, hay que reconocer que lo fundamental en Mateo, es precisamente ser una voz de aliento para quien se encuentra en el sufrimiento. Hoy parece que no ha perdido esta perícopa su efectividad, en cuanto que invita al hombre a volver a Dios, ya que Él es el único que puede ser alivio en la tormenta y la tribulación. Es quien puede hacer comprender al hombre que hay un elemento de trascendencia y de promesa de paz, más allá de la situación inmediata en la que se está viviendo. Las bienaventuranzas en Mateo "se nos presentan como un programa de vida cristiana. No quieren sencillamente enseñarnos quién es 
dichoso, sino quizá sobre todo cómo hay que obrar para participar de esa dicha" (Dupont, 1997; p. 38)

Por tanto, aunque hay una marcada tendencia en la afirmación de la dignidad desde una perspectiva ontológica, tanto filosófica como teológicamente, hay que decir que, también se evidencia aquí la dignidad moral, porque el hombre con sed de justicia busca una mejor vida. Y es que precisamente, las palabras de Jesús son esenciales para que el hombre haga de su vida, una que posea valor en sí misma; lo cual indica que su obrar independientemente de la situación de injusticia, sufrimiento y pobreza en que se viva, sea un espacio propicio para hacerse reconocer como un ser igual a quien no está en una situación parecida.

\section{Las Bienaventuranzas para América Latina}

Como ya se ha reflexionado sobre la importancia tácita que se da a la dignidad en las bienaventuranzas, es importante no quedarse en una reflexión de tal índole. Lo que encamina esta investigación es definitivamente la posibilidad de que las bienaventuranzas sean comprendidas en la sociedad latinoamericana, sociedad que vive en el sufrimiento, la desigualdad, la injusticia y la incertidumbre, sin quedarse solamente en la afirmación categórica de que toda persona tiene dignidad.

La búsqueda teológica debe hacer factible la pretensión de una propuesta de bienaventuranzas, para esta sociedad que se lamenta. No quiere decir esto, que la Sagrada Escritura pierda su validez, sino que la lectura o hermenéutica que se hace de ella, en ocasiones suele ser interpretada sin tener en cuenta las situaciones contextuales de quien se acerca a la Palabra; no hace concreto y vivo el mensaje salvífico de Cristo para con este pueblo; ya que, la Palabra debe hacerse viva en nuestra realidad, debe germinar en la realidad para que sea cada vez más salvífica.

Desde esta intencionalidad expuesta, es un imperativo dejar de formular o interpretar las Bienaventuranzas, para recordar algo evidente: que el pobre, marginado y todo aquel que sufre, tiene dignidad; se hace necesario interpelar a aquel que contempla acomodadamente el sufrimiento del otro, y más si se dice cristiano. De esta manera, para aquellos que sienten la compasión, misericordia y gratuidad de Dios, en Latinoamérica, podemos hacer la siguiente propuesta de bienaventuranzas ${ }^{3}$ :

3 Es importante aclarar que esta propuesta de bienaventuranzas surge de la experiencia misionera que he vivido como religioso de la Orden de Predicadores. De la imposibilidad, en 
- $\quad$ Bienaventurados los que sufren al ver el hambre y la injusticia en los más pobres, porque con sus obras ayudan a vivir el Reino de los Cielos en la misma tierra.

- Bienaventurados aquellos que sufren por ver cómo sus hermanos viven esclavizados en un mundo hedonista y materialista, en donde lo individual es lo que se convierte en valor fundamental, porque con su oración y ejemplo de vida darán de qué hablar para cambiar ese marcado individualismo.

- Bienaventurados los que no tienen pan para comer, agua para beber y techo en el que vivir, porque comprenderán que en personas altruistas y filántropos, organizaciones e instituciones de proyección social, está Dios actuando.

- Bienaventurados los que sufren por las profanaciones y blasfemias hechas a su dignidad por ser de condición económica lamentable, porque entenderán que el dinero no es requisito para ser dignos.

- Bienaventurados los que lloran a causa de la injusticia y desigualdad social, los que sufren la ausencia de gobernantes para ayudar con las situaciones de desplazamiento y pobreza absoluta, porque ellos estarán en la presencia de Dios, al comprender que Él no es sus gobernantes.

- Bienaventurados los que no son escuchados, porque sabrán que sus palabras revelan la verdad de Dios en la historia.

Estas bienaventuranzas más que ver la esperanza en el Reino de los Cielos, como comúnmente se suelen interpretar, desde una perspectiva de consuelo conformista, intentan ser respuesta contextual a situaciones, para las que Dios en su amor gratuito actúa, no al brindar solo una esperanza futura, sino inmediata. Hay que hacer relación de las experiencias de vida tanto de quien ofrece como de quien recibe; pues, Dios actúa en ambos. La acción de Dios, en quien da, muestra que el hombre es capaz de amar al otro a tal punto de dar de sí para que el otro surja; y la acción de Dios, en quien recibe, es mostrar su rostro humilde que permite que se reconozca, que sin tener en cuenta condición social, política y económica, todos somos hijos de Dios.

Por consiguiente, los pobres son una forma de hablar de Dios en medio de las realidades contextuales de la sociedad latinoamericana. Más que hacer uso,

ocasiones, de hablar de Dios en determinados contextos, tal vez porque los intereses de la gente se centraban más en las necesidades básicas, que en lo trascendente. 
es vivir el lenguaje profético y el lenguaje de la contemplación de los que habla Gutiérrez (1986).

\section{Conclusión}

Una de las pretensiones de este trabajo es ver que la dignidad tanto en lo ontológico como en lo moral, es un aspecto inherente al hombre. Y esto es fundamental para una sociedad como la Latinoamericana, en donde se considera que el hombre digno es solo aquel a quien la vida le ha brindado oportunidades de estudio, casa, riqueza, entre otras.

Por tanto, son tres los aspectos fundamentales que comprenden la noción de dignidad:

a. El ser humano es un fin, en y para sí mismo, no es un medio y aunque en ocasiones haga de tal; por ejemplo, cuando se habla en un ámbito de producción laboral, como el de obrero en que es medio para producir algo, no puede reducirse su vida a esto, ya que lo que define su ser no es el ser obrero, sino el ser persona.

b. El respeto incondicional, debido a que somos personas y no objetos de utilidad, gozamos de un valor irremplazable, no como los objetos que cuando termina la duración de su utilidad son desechados.

De allí que el respeto sea el fundamento de la dignidad, pues la persona 'es cuerpo' y no 'tiene cuerpo', razón por la cual reacciona cuando se quieren aprovechar de ella como simple cuerpo, así mismo pasa "cuando siente que quieren negar su vida interior, su intimidad, cuando percibe que tratan de reducir su libertad, que limitan sus posibilidades de comunicarse y amar" (González, 2007; 49).

c. La persona es sujeto de la valoración moral, puesto que "el juicio moral que distingue entre lo bueno y lo malo es un acto propio y exclusivo de la persona humana" (González, 2007; 49). Esto indica que esta soberanía que posee el hombre tiene dos momentos que son: el hombre como legislador de la conducta y las normas morales establecidas como paso para el logro de su propia felicidad.

Basta con afirmar que estos tres aspectos son integradores de todo el ser humano y significan que la vida del hombre sobresale por encima de cualquier estructura o mediación institucional. Para poder entender esto es necesario situarnos en una perspectiva contemporánea en donde a partir de la autonomía 
de la razón el hombre ha adquirido una posibilidad de decisión independiente, según Kant, de cualquier elemento que sea opresor.

Podría decirse, sin embargo, que estos tres aspectos tienen un elemento unificador para el cristiano, y ese elemento es tener como centro a Dios, así, "el ser humano tiene una dignidad que le viene dada por el hecho de ser creado a imagen y semejanza de Dios, por el hecho de establecer con Él una alianza de amor y de amistad y de orientarse existencialmente hacia Dios" (Torralba, 2005; p. 91). Es decir, que Dios se convierte para el hombre en la causa primera y también en la causa final de su existencia, y además en el sustento y razón de su dignidad.

Hay que tener en cuenta, entonces, que esta perspectiva teológica abarca lo que se comprende como dignidad ontológica y dignidad moral, para afirmar que:

Desde la teología y a la luz de la Biblia, la creación del hombre y de la mujer a imagen de Dios (Gn 1,27) les otorga una dignidad indiscutible, corroborada por el hecho de que el Creador reivindique para sí el tutelar su vida (Gn 4,9-15; 9,5), proclame una relación personal con cada uno (Is 43,1) y lo haya amado hasta hacerse Él mismo hombre en la persona del hijo y dar su vida por él (Gal 2,20) (Cuyás, 1997; p. 31).

Por tanto, hablar de esta perspectiva de dignidad teológica es vislumbrar que el hombre, por ser creado se le otorga la dignidad como un regalo, en el que debe vivir conforme a él e implica que por medio de su obra y acción, de su deseo para actuar y superarse, debe hacerse más próximo a Dios.

Se trata de entender que Dios, en un sentido más profundo, quiere que el hombre pueda liberarse de estereotipos que excluyen y alienan a quien se encuentra en situación de sufrimiento e injusticia. Esto, tanto para quien sufre como para quien no. Es un trabajo que no se reduce a una parte de la población, en una división desagradable, ricos y pobres, sino que bajo la premisa de ser hijos de Dios y poseedores de reconocimiento y amor, puedan plantearse mecanismos de solución a situaciones que no favorecen a ningún hombre que viva en sociedad, especialmente de la latinoamericana.

Por consiguiente, lo principal a lo que se quiere exhortar es a que la diferencia no sea un factor determinante para excluir, como la diferencia entre rico y pobre, sino que sea una oportunidad para reconocer que Dios quiere que haya unidad, por medio de la solidaridad y generosidad. Es vislumbrar que no hay mayor felicidad que saberse amado por Dios, que la acción de Dios está presente en quien tiende una mano en momentos de dolor y tribulación.

Que la dignidad es liberación que supera los parámetros establecidos por el mismo hombre, donde quien vale es quien está en prosperidad, parámetros 
que dividen sociedades, parámetros que son unilaterales y evitan la posibilidad de construcción social. Parámetros que no evidencian la acción gratuita de Dios para con el hombre.

De esta manera, es preciso tener en cuenta que las bienaventuranzas para el hombre latinoamericano constituyen una propuesta que bajo la acción de Dios permiten la transformación de la conciencia que hace que las situaciones de sufrimiento y dolor no sean motivos de cambios. Sean la oportunidad para que el hombre que se reconoce hijo de Dios descubra que su acción misericordiosa está en detalles que a veces son incomprensibles a la propia razón humana.

\section{Referencias}

Biblia de Jerusalén (1998). Bilbao, Casa Editorial Desclée de Brouwer.

Cuyás, M. (1997): Cuestiones de bioética. Barcelona, Mapfre Medicina-Institut Borja de Bioética.

Dupont, J. (1997): El mensaje de las bienaventuranzas. Navarra, Casa Editorial Verbo Divino.

Fuster C., I. (2010): Persona y libertad. Barcelona, Editorial Balmes.

González \& Marquínez. (2007): Valores éticos para la convivencia. Bogotá D.C. Editorial el Búho.

Gutiérrez, G. (1986): Hablar de Dios desde el sufrimiento del inocente, una reflexión sobre el libro de Job. Lima, Instituto Bartolomé de Las Casas.

Gutiérrez, G. (1989): Teología y liberación, perspectivas y desafíos, ensayos en torno a la obra de Gustavo Gutiérrez. Perú, Instituto Bartolomé de las Casas.

Lepeley, J. (1987): Hacia una Iglesia de los pobres. Centro de estudios para el desarrollo e integración de América Latina. Bogotá, CELAM.

López, T. (1974): Teología liberadora en América Latina. Ediciones Paulinas.

Rahner, K. (1961): Escritos de Teología II. Madrid, Editorial Taurus.

Sobrino, J. (1982): Jesús en América Latina. Santander, Editorial Sal Terrae.

Torralba, F. (2005): ¿Qué es la dignidad humana? Barcelona, Editorial Herder.

Revista cuestiones teológicas. (2013). Medellín, Editorial Universidad Pontificia Bolivariana, vol. 40, $\mathrm{n}^{\circ} 93$.

Revista cuestiones teológicas. (2014). Medellín, Editorial Universidad Pontificia Bolivariana, vol. 41, $\mathrm{n}^{\circ} 95$. 